\title{
COMPARATIVE ANALYSIS OF PASSENGER RIDE COMFORT USING VARIOUS SEMI- ACTIVE SUSPENSION ALTERNATIVES
}

\author{
Devdutt $^{1}$ and M.L. Aggarwal ${ }^{2}$ \\ ${ }^{1,2}$ Department of Mechanical Engineering, YMCAUST, Faridabad, India
}

\begin{abstract}
In this paper, different semi-active control strategies for non-linear quarter car model equipped with controllable magneto-rheological (MR) shock absorbers and fuzzy logic controller are compared. Polynomial model is selected to characterize the experimental results of MR shock absorber. A combination of Forward Fuzzy Logic Controller (FFLC) and Inverse Fuzzy Logic Controller (IFLC) is designed for proper working of MR shock absorber i.e. generation and supply of control current to MR shock absorber, which provides damping force to suspension system for vibration control purpose. Simulink responses of four different cases are evaluated for passenger ride comfort analysis taking uncontrolled, primary suspension controlled, secondary suspension controlled and fully controlled quarter car models. The obtained results in graphical and mathematical form demonstrate that the fully controlled quarter car system provides excellent performance in suppression of passenger seat vibrations compared to other control strategies while the vehicle travels over the sinusoidal type of input road profile.
\end{abstract}

\section{KEYWORDS}

Quarter car model, Fuzzy Logic Control, Passenger seat vibrations, MR suspension system

\section{INTRODUCTION}

Vehicle performance in terms of passenger ride comfort and safety as well as vehicle handling issues is affected by the application of passive, semi-active or active suspension system based technology. With the passage of time, advancements in the areas of automotive sector related industries are responsible for elimination of traditional or uncontrollable passive suspension systems having limited capability in delivering desired results as per customer's requirements and expectations. Active suspension systems can fulfil the conflicting demands in terms of ride comfort and vehicle handling up to maximum level but cost factor as well as assembled complicated sensors, actuators and other devices poses major hindrance in their wide spread implementation in vehicles. Semi-active suspension system is the promising future, having better performance compared to passive suspension system and less costly than active suspension technology [1-2].

Recently, research and development related to working and controllable behaviour of magnetorheological (MR) absorbers has resulted into its selection and application in various devices ranging from civil structures, seat suspensions and military weapons and vehicles [3-6]. Damping behaviour controlling of MR shock absorber in semi-active suspension system is based on the working of the assembled two controllers, where first controller generates desired damping force signal whereas second controller is responsible for supplying the command current to MR shock absorber. In past, various control strategies have been studied related to vibration control applications in semi-active suspension systems such as H-infinity control [7], sliding mode 
control [8], fuzzy logic control [9], adaptive control [10], neural network control [11] and skyhook, ground-hook and hybrid control [12] etc.

MR shock absorbers are known for generating hysteretic results having nonlinear characteristics, which needs to be modelled for development of control system. This unpredictable nonlinear hysteretic nature of MR shock absorber during damping force generation period makes its selection and control system development a challenging and demanding task for control system engineers and automotive manufacturers. In past, several parametric and non-parametric models have been proposed by different researchers. These models include Bouc-Wen hysteresis model [13], fuzzy model [14], polynomial model [15], LuGre model [16], neural network model [1718], viscoelastic-plastic model [19], sigmoid function-based model [20] and adaptive neuro-fuzzy inference system [21] etc. Out of the various mentioned models, polynomial model is highly suitable for development of forward as well as inverse model of MR shock absorbers, which is helpful for its proper working in vibration control applications in vehicle systems.

In this paper, firstly experimental work is performed on selected MR shock absorber under various excitation conditions and current values while polynomial model is selected to characterize the experimental results of the MR shock absorber. Fuzzy controller is developed which is the combination of Forward and Inverse Fuzzy Logic Controller for supplying the command current signal to MR shock absorber. Further, a fully controlled semi-active quarter car system is constructed with three degrees of freedom, having one MR shock absorber in primary suspension system while second in secondary suspension system. Finally, simulation work is performed and compared for four different control strategies of quarter car model under sinusoidal type of input road excitation, keeping passengers ride comfort into account in terms of passenger seat acceleration and displacement results.

\section{POLYNOMIAL MODELLING}

The prototype selected for experimental work is RD-1005-3, a product developed by Lord Corporation, USA whereas its technical parameters can be found in [7]. The MTS (Material Testing System) machine generated test results of MR shock absorber in terms of ForceDisplacement and Force-Velocity curves at one particular test condition of $3 \mathrm{~Hz}$ and $\pm 2.5 \mathrm{~mm}$ using different intensities of supplied current ranging from 0-1 A with increment of $0.25 \mathrm{~A}$, are shown in Figure 3 (a) - (b) respectively.

Table 1. Calculated coefficients $b_{i}$ and $c_{i}$ of fitted curve with values

\begin{tabular}{|c|c|c|c|c|c|c|c|}
\hline \multicolumn{4}{|c|}{ Positive acceleration } & \multicolumn{4}{|c|}{ Negative acceleration } \\
\hline & Coefficients & \multicolumn{2}{|c|}{ Coefficients } & \multicolumn{2}{|c|}{ Coefficients } & \multicolumn{2}{|c|}{ Coefficients } \\
\hline$b_{0}$ & -37.25 & $c_{0}$ & -465.33 & $b_{0}$ & 37.37 & $c_{0}$ & 467.92 \\
\hline$b_{1}$ & 2.07 & $c_{1}$ & 8.46 & $b_{1}$ & 2.80 & $c_{1}$ & 5.54 \\
\hline$b_{2}$ & 0.06 & $c_{2}$ & 0.98 & $b_{2}$ & -0.08 & $c_{2}$ & -0.74 \\
\hline$b_{3}$ & $2.30 \mathrm{E}-03$ & $c_{3}$ & 0.07 & $b_{3}$ & $2.25 \mathrm{E}-03$ & $c_{3}$ & $7.21 \mathrm{E}-02$ \\
\hline$b_{4}$ & $-3.82 \mathrm{E}-05$ & $c_{4}$ & $-6.42 \mathrm{E}-04$ & $b_{4}$ & 8.91E-05 & $c_{4}$ & $1.73 \mathrm{E}-04$ \\
\hline$b_{5}$ & $-1.59 \mathrm{E}-06$ & $c_{5}$ & $-9.16 \mathrm{E}-05$ & $b_{5}$ & $-4.35 \mathrm{E}-06$ & $c_{5}$ & $-8.65 \mathrm{E}-05$ \\
\hline$b_{6}$ & $-3.04 \mathrm{E}-09$ & $c_{6}$ & $1.26 \mathrm{E}-07$ & $b_{6}$ & $-3.00 \mathrm{E}-08$ & $c_{6}$ & $1.64 \mathrm{E}-07$ \\
\hline$b_{7}$ & $2.04 \mathrm{E}-10$ & $c_{7}$ & 4.57E-08 & $b_{7}$ & $2.66 \mathrm{E}-09$ & $c_{7}$ & 4.02E-08 \\
\hline$b_{8}$ & 4.97E-12 & $c_{8}$ & $2.83 \mathrm{E}-12$ & $b_{8}$ & $1.83 \mathrm{E}-12$ & $c_{8}$ & $-6.06 \mathrm{E}-11$ \\
\hline$b_{9}$ & $5.62 \mathrm{E}-14$ & $c_{9}$ & $-7.92 \mathrm{E}-12$ & $b_{9}$ & $-5.20 \mathrm{E}-13$ & $c_{9}$ & $-6.58 \mathrm{E}-12$ \\
\hline
\end{tabular}


In order to prove the applicability of selected polynomial model for control system development purpose, the experimental test results and the fitted curves are shown in Figure 1 while the calculated mathematical magnitudes of the coefficients $b_{i}$ and $c_{i}$ are tabulated Table 1 . It can be concluded that the fitted curves using polynomial model and the experimental test curves show very good closeness with each other.

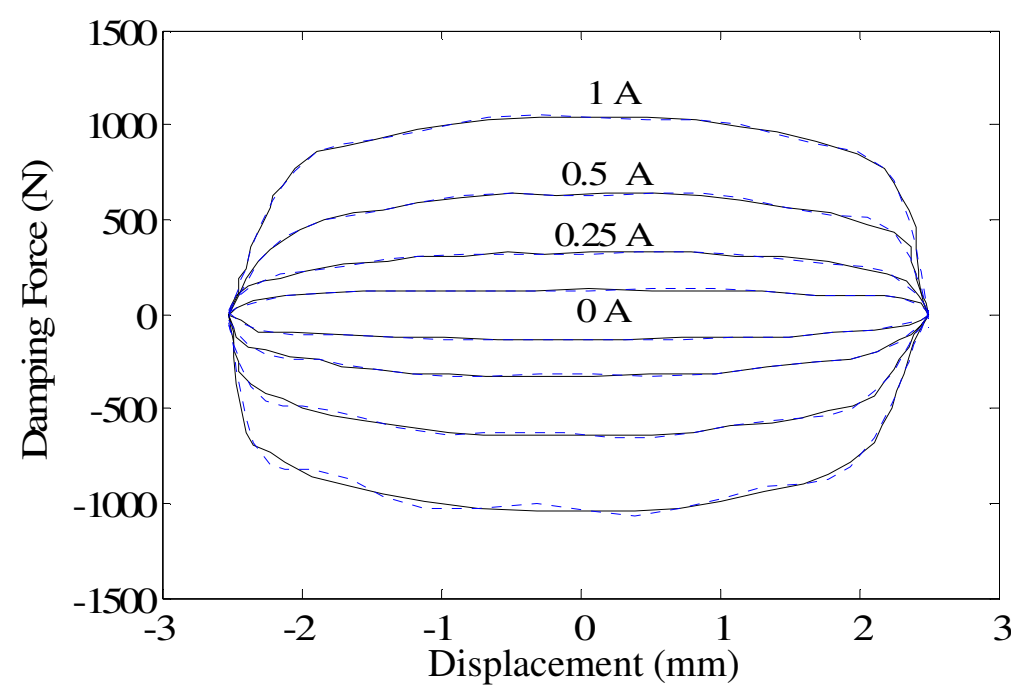

(a) Force vs Displacement

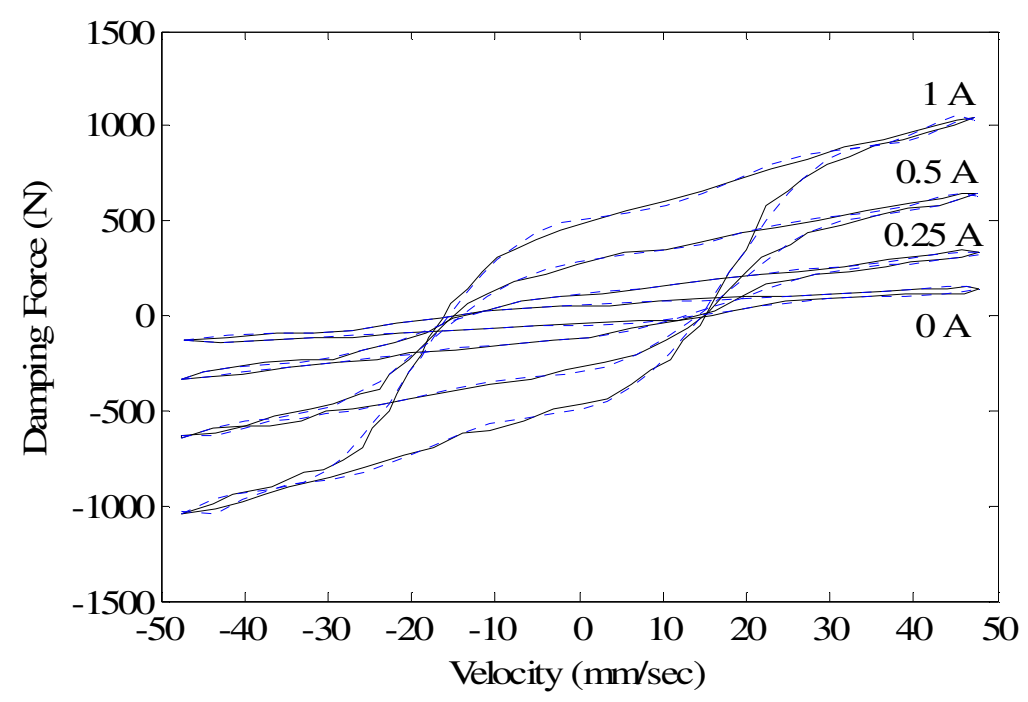

(b) Force vs Velocity

Figure 1. The comparison between polynomial model and experimental results $(3 \mathrm{~Hz}, \pm 2.5 \mathrm{~mm}):($ Measured, - - - Simulated $)$ 


\section{SEMI-ACTIVE QUARTER CAR MODEL}

A semi-active quarter car model is developed having assembly of MR shock absorbers as shown in Figure 2, representing one-fourth body mass of the complete vehicle. Present nonlinear structure is assembly of passenger seat mass, sprung mass and unsprung mass $\left(m_{1}, m_{2}, m_{3}\right)$, primary suspension with spring of stiffness and shock absorber damping coefficient $\left(k_{1}, c_{1}\right)$, secondary suspension with spring of stiffness and shock absorber damping coefficient $\left(k_{2}, c_{2}\right)$ and tire stiffness $\left(k_{t}\right)$ respectively. The vertical displacement of passenger seat, sprung mass and unsprung mass and road input is represented by $z_{1}, z_{2}, z_{3}$ and $z_{r}$ respectively. Here, Figure 2 shows the fully controlled quarter car model where MR shock absorber 1 is assembled in primary suspension system responsible for generating damping force as $F_{M R 1}$ and MR shock absorber 2 is assembled in secondary suspension system responsible for generating damping force as $F_{M R 2}$. When in fully controlled suspension system, MR shock absorber 1 is replaced by passive shock absorber then it represents secondary suspension controlled system. While if MR shock absorber 2 is replaced by passive shock absorber then it represents primary suspension controlled system. Present model performs as semi-active suspension when the supplied current to MR shock absorber is greater than zero while in case of control system failure, suspension system can still work as fail safe device matching the performance of passive suspension system.

The vertical equations of motion of designed quarter car model with three-degree-of-freedom taking passenger seat mass, sprung mass and unsprung mass are given by :

$$
\begin{aligned}
& m_{1} \ddot{z}_{1}+c_{2}\left(\dot{z}_{1}-\dot{z}_{2}\right)+k_{2}\left(z_{1}-z_{2}\right)+F_{M R 2}=0 \\
& m_{2} \ddot{z}_{2}-c_{2}\left(\dot{z}_{1}-\dot{z}_{2}\right)-k_{2}\left(z_{1}-z_{2}\right)+c_{1}\left(\dot{z}_{2}-\dot{z}_{3}\right)+k_{1}\left(z_{2}-z_{3}\right)-F_{M R 2}+F_{M R 1}=0 \\
& m_{3} \ddot{z}_{3}-c_{1}\left(\dot{z}_{2}-\dot{z}_{3}\right)-k_{1}\left(z_{2}-z_{3}\right)+k_{t}\left(z_{3}-z_{r}\right)-F_{M R 1}=0
\end{aligned}
$$

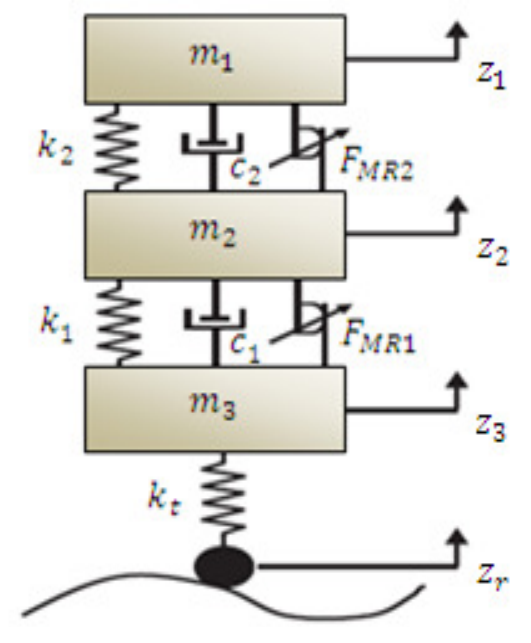

Figure 2. Quarter car model with MR suspension systems

\section{FORMULATION OF FUZZY CONTROLLER}

The concept of fuzzy logic is helpful in control system problems where exact mathematical model formulation is not feasible as well as for systems having very complex dynamics. In practical problems related to industrial sectors, design and development person responsible for fuzzy 
controller working should have knowledge and expertise about the behavior of the system to be controlled in particular situation. Basically, fuzzy controller working is dependent on the number of input-output selection, membership function shapes and rule base writing, which is directly implemented in control system, based on expert's knowledge. In present study, controller structure is dependent on the signals supplied by quarter car model, representing MISO (Multiple Input Single Output) type system.

A general design structure of assembled fuzzy controller in primary suspension system with various stages of supplied signals with direction for its working in considered semi-active quarter car model is shown in Figure 3 (a) - (b) respectively. Here, Forward Fuzzy Logic Controller (FFLC) is supplied with two signals in terms of sprung mass velocity $\left(V_{S}\right)$ and primary suspension velocity $\left(V_{r e l 1}\right)$ and generates the desired damping force signal $\left(F_{d 1}\right)$ while Inverse Fuzzy Logic Controller (IFLC) is supplied with two signals as desired damping force signal and primary suspension velocity while the output signal generating from it is the control current $\left(I_{1}\right)$ which is later on supplied to physical MR shock absorber 1 (MR1) for generating real damping force in suspension system.

The membership function shapes with the interval period for Forward and Inverse Fuzzy Logic Controller working in primary suspension system is shown in Figure 4 and Figure 5 respectively. Normalized values are multiplied by scaling factors to obtain the real intervals of supplied signals. The abbreviations selected for membership functions are as follows: Negative Large [NL], Negative Medium [NM], Negative Small [NS], Zero [ZR], Positive Small [PS], Positive Medium [PM], Positive Large [PL], Positive Very Large [PVL], Positive Very Very Large [PVVL]. The written rules, responsible for performance delivery of FFLC and IFLC in considered case, are shown in Table 2 and Table 3 respectively.

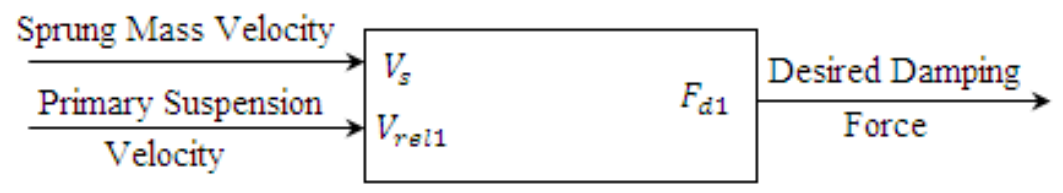

(a) Forward Fuzzy Logic Controller

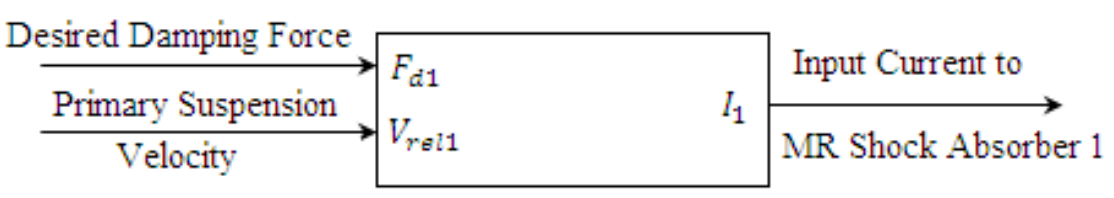

(b) Inverse Fuzzy Logic Controller

Figure 3. Block diagram of Fuzzy Logic Controller in Primary Suspension System 
International Journal of Recent advances in Mechanical Engineering (IJMECH) Vol.3, No.3, August 2014

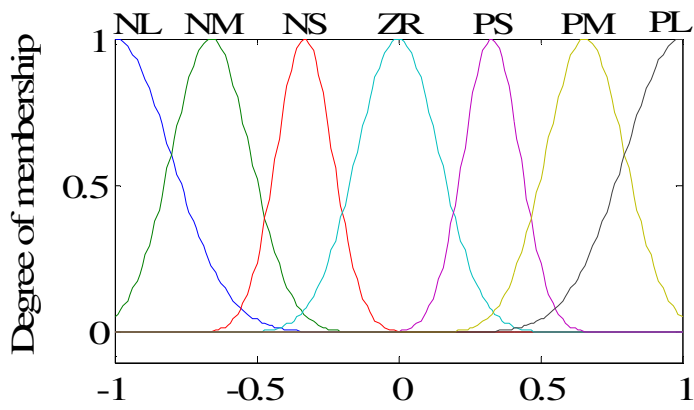

(a)

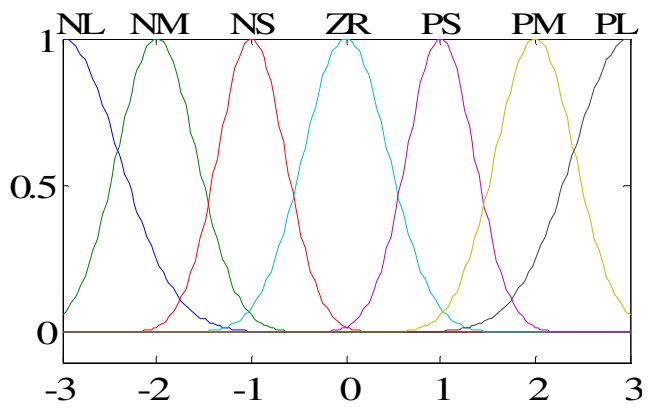

(b)

Figure 4. MFs for FFLC 1 (a) Input side, $V_{s}$ and $V_{\text {rel1 }}$ (b) Output side, $F_{d 1}$

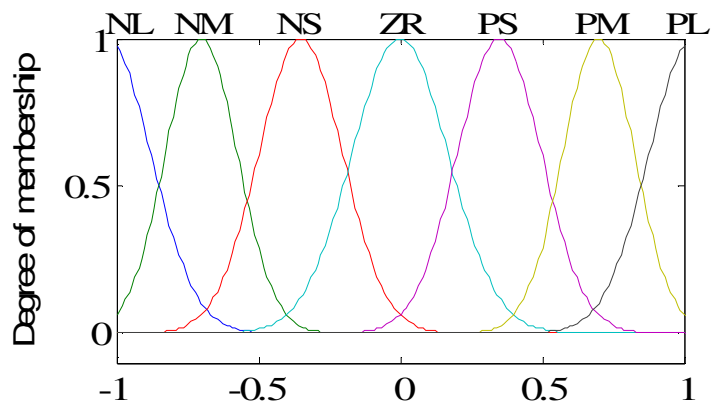

(a)

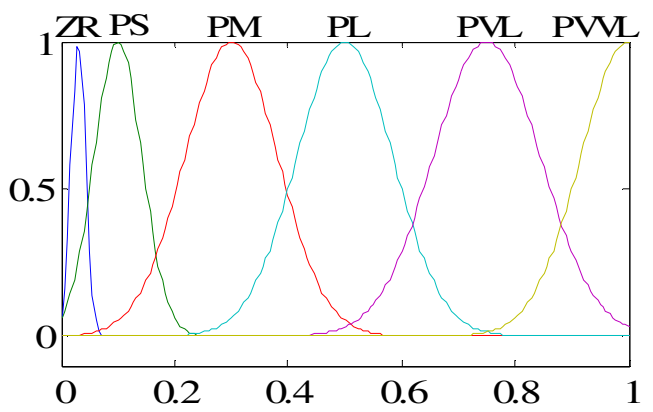

(b)

Figure 5. MFs for IFLC 1 (a) Input side, $V_{\text {rel1 }}$ and $F_{d 1}$ (b) Output side, $I_{1}$

Table 2. Forward Fuzzy rule base for computing $F_{d 1}$

\begin{tabular}{cccccccc}
\hline$V_{S} / V_{\text {rel1 }}$ & $N L$ & $N M$ & $N S$ & $Z R$ & $P S$ & $P M$ & $P L$ \\
\hline$N L$ & $\mathrm{PL}$ & $\mathrm{PL}$ & $\mathrm{PL}$ & $\mathrm{PL}$ & $\mathrm{PM}$ & $\mathrm{PS}$ & $\mathrm{ZR}$ \\
$N M$ & $\mathrm{PL}$ & $\mathrm{PL}$ & $\mathrm{PL}$ & $\mathrm{PM}$ & $\mathrm{PS}$ & $\mathrm{ZR}$ & $\mathrm{NS}$ \\
$N S$ & $\mathrm{PL}$ & $\mathrm{PL}$ & $\mathrm{PM}$ & $\mathrm{PS}$ & $\mathrm{ZR}$ & $\mathrm{NS}$ & $\mathrm{NM}$ \\
$Z R$ & $\mathrm{PL}$ & $\mathrm{PM}$ & $\mathrm{PS}$ & $\mathrm{ZR}$ & $\mathrm{NS}$ & $\mathrm{NM}$ & $\mathrm{NL}$ \\
$P S$ & $\mathrm{PM}$ & $\mathrm{PS}$ & $\mathrm{ZR}$ & $\mathrm{NS}$ & $\mathrm{NM}$ & $\mathrm{NL}$ & $\mathrm{NL}$ \\
$P M$ & $\mathrm{PS}$ & $\mathrm{ZR}$ & $\mathrm{NS}$ & $\mathrm{NM}$ & $\mathrm{NL}$ & $\mathrm{NL}$ & $\mathrm{NL}$ \\
$P L$ & $\mathrm{ZR}$ & $\mathrm{NS}$ & $\mathrm{NM}$ & $\mathrm{NL}$ & $\mathrm{NL}$ & $\mathrm{NL}$ & $\mathrm{NL}$ \\
\hline
\end{tabular}

Table 3. Inverse Fuzzy rule base for computing $I_{1}$

\begin{tabular}{cccccccc}
\hline$F_{d 1} / V_{\text {rel1 }}$ & $N L$ & $N M$ & $N S$ & $Z R$ & $P S$ & $P M$ & $P L$ \\
\hline$N L$ & PVVL & PVL & PVL & PL & PM & PS & ZR \\
$N M$ & PVL & PVL & PL & PM & PS & ZR & PS \\
$N S$ & PVL & PL & PM & PS & ZR & PS & PM \\
$Z R$ & PL & PM & PS & ZR & PS & PM & PL \\
$P S$ & PM & PS & ZR & PS & PM & PL & PVL \\
$P M$ & PS & ZR & PS & PM & PL & PVL & PVL \\
$P L$ & ZR & PS & PM & PL & PVL & PVL & PVVL \\
\hline
\end{tabular}


Here, Mamdani method is selected with "Min - Max" fuzzy inference state and Centroid method is applied for conversion of linguistic variables to mathematical values in defuzzification stage.

\section{SIMULATION RESULTS}

In this section, simulation work is performed on quarter car models, designed with different four types of suspension alternatives whereas the selected parameters are tabulated in Table 4. The main interest of study is to evaluate passenger ride comfort response taking acceleration and displacement of passenger seat into account. Sinusoidal road excitation with $10 \mathrm{rad} / \mathrm{sec}$ was developed as input to travelling vehicle system as shown in Figure 6.

Table 4. Parameters of quarter car model for simulation

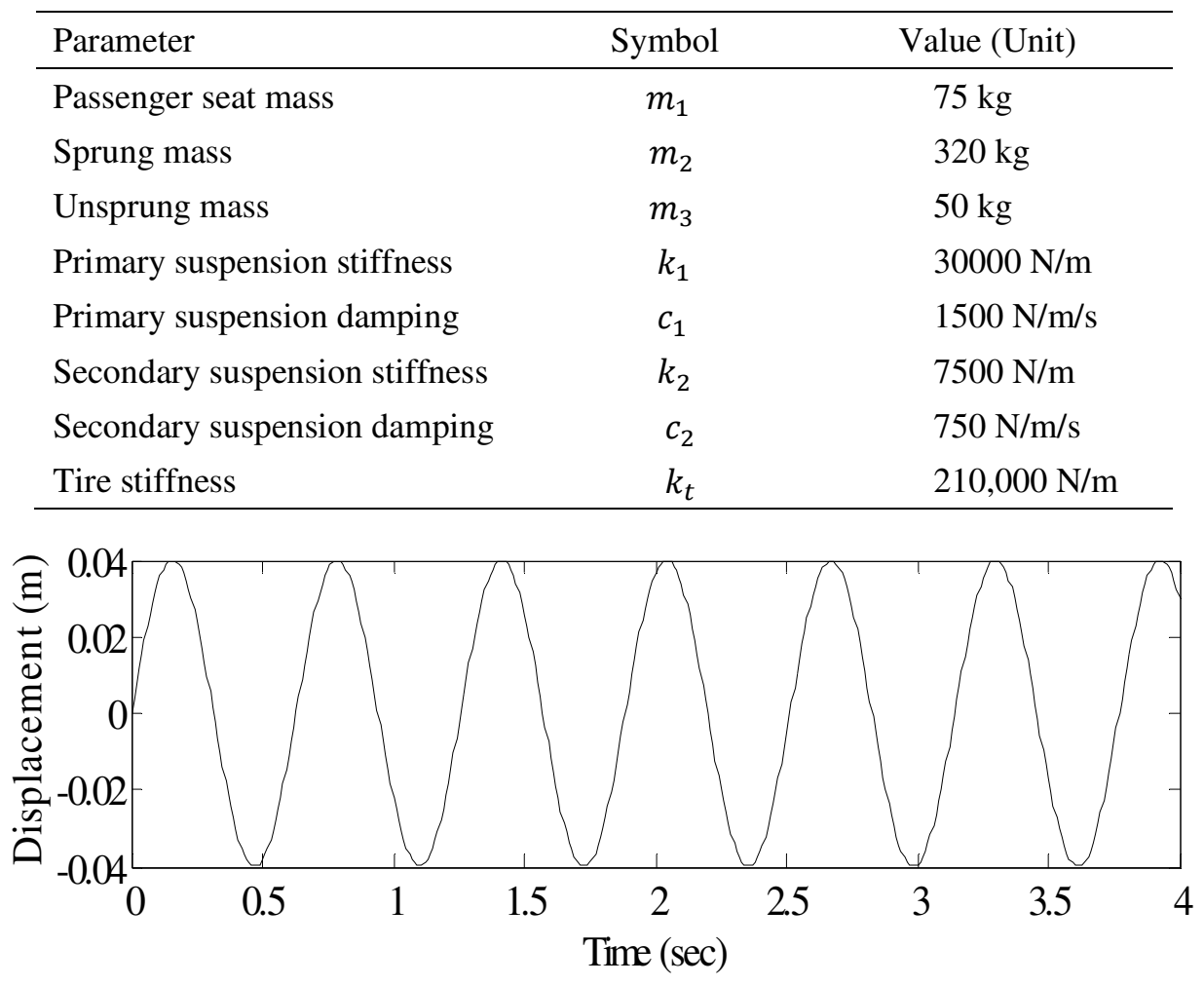

Figure 6. Input road excitation of sinusoidal type with $10 \mathrm{rad} / \mathrm{sec}$

The vibration response in time domain of passenger seat in vertical direction is shown in Figure 7 having the comparison response of controlled and uncontrolled cases. As can be seen that all three different controlled cases provide improved performance compared to uncontrolled case taking quarter car model into account in terms of passenger seat acceleration and displacement response. It can also be observed that the fully controlled system provides maximum reduction in acceleration and displacement response of passenger seat compared to other control strategies. 

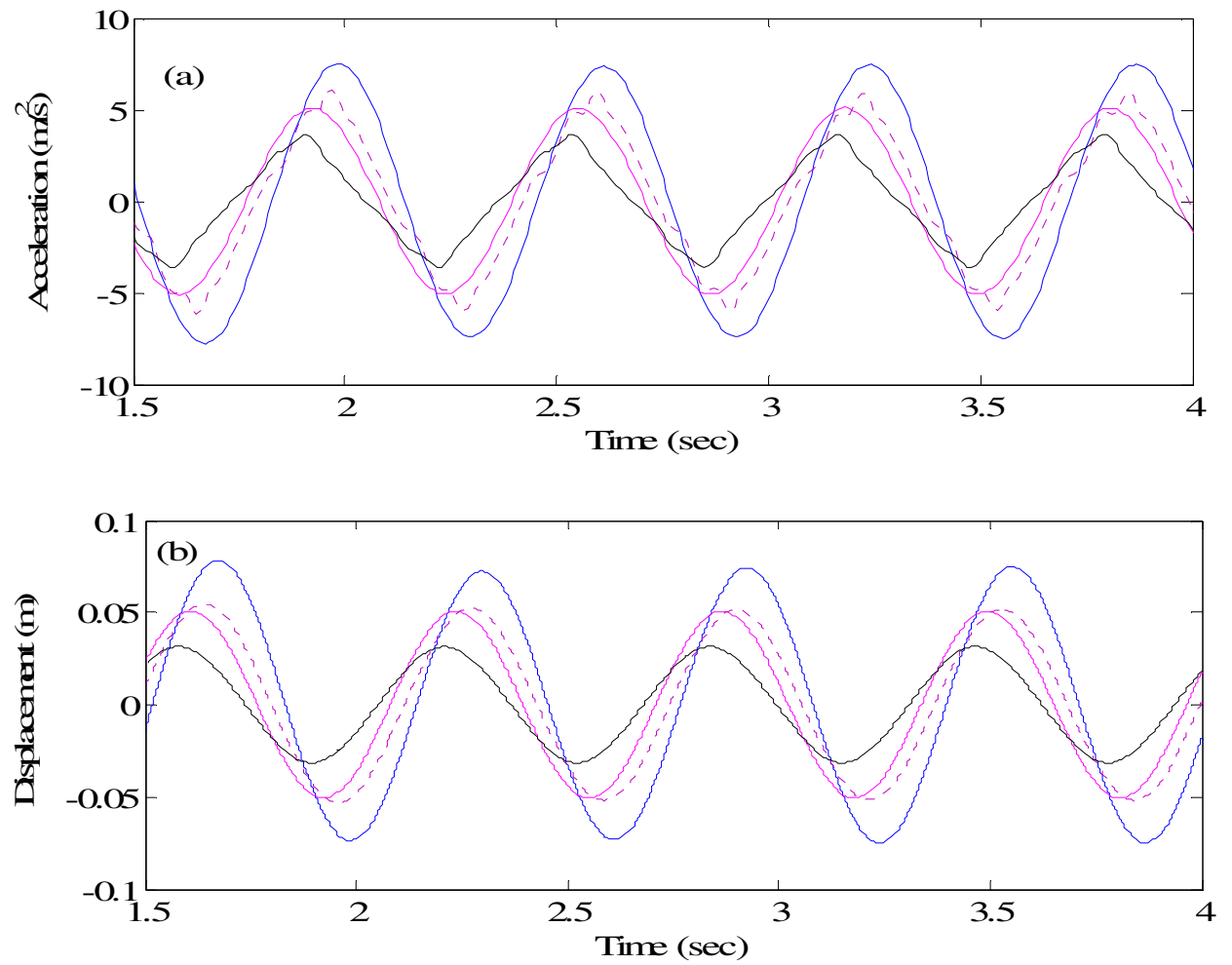

Figure 7. Passenger seat response under sinusoidal type road excitation: (a) passenger seat acceleration, (b) passenger seat displacement; ( _ Uncontrolled, _ Primary suspension controlled, ----- Secondary suspension controlled, _ Fully controlled)

Damping force response as well as the supplied current to the assembled MR shock absorbers in different controlled cases is shown in Figure 8 - Figure 11 respectively. It can be observed from

Figure 8 (a) and Figure 10 (a) that the magnitude of damping force generated by assembled MR shock absorber in primary suspension system remains below $1000 \mathrm{~N}$ during compression and rebound stroke while the magnitude of supplied current responsible for its generation remains below maximum safe limit of 1 A. Similarly, Figure 9 (a) shows the variation of magnitude of damping force between the limits of $500 \mathrm{~N}$ for compression and rebound stage as generated by MR shock absorber assembled in secondary suspension of secondary controlled suspension system while Figure 9 (b) represents the signal of supplied current to it. The values of generated damping force by MR shock absorber and supplied current value to it remains at minimum level for secondary suspension assembled MR shock absorber as shown in Figure 11 (a)-(b) respectively, while fully controlled suspension system is taken into account.
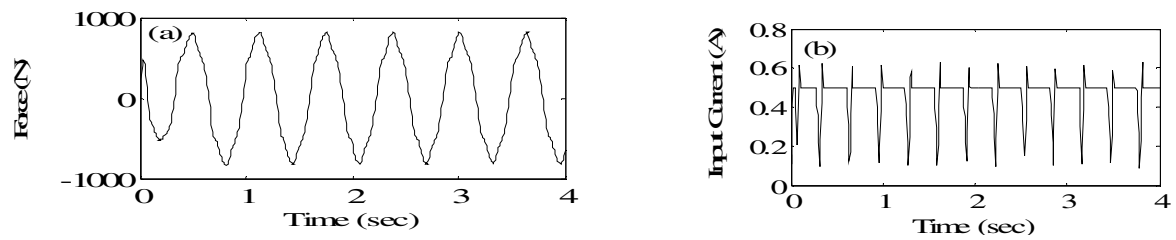

Figure 8. Response plots of primary suspension MR shock absorber for Primary Suspension Controlled System: (a) desired damping force signal (b) supplied control current signal 
International Journal of Recent advances in Mechanical Engineering (IJMECH) Vol.3, No.3, August 2014
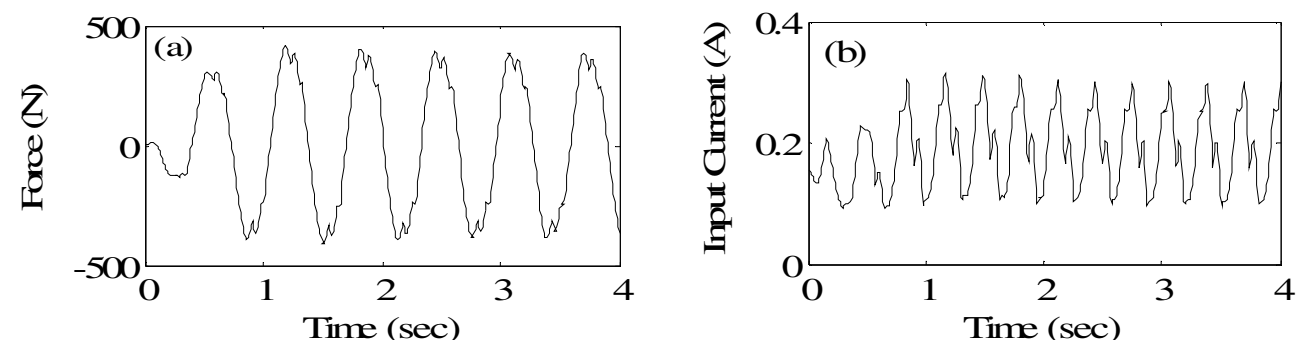

Figure 9. Response plots of secondary suspension MR shock absorber for Secondary Suspension Controlled
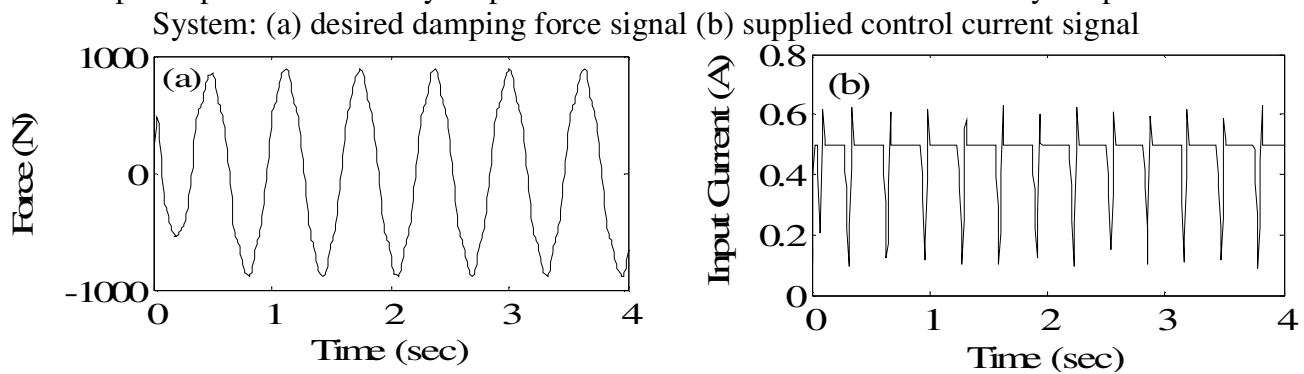

Figure 10. Response plots of primary suspension MR shock absorber for Fully Controlled Suspension System: (a) desired damping force signal (b) supplied control current signal
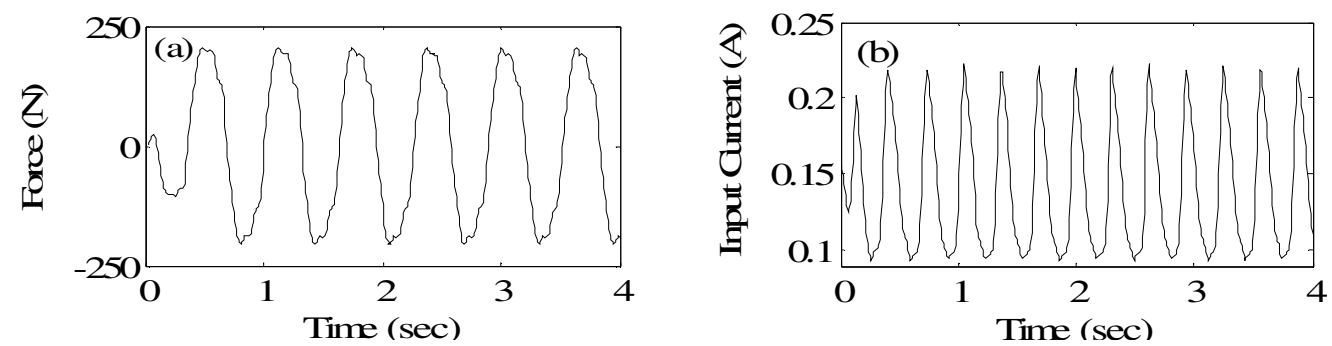

Figure 11. Response plots of secondary suspension MR shock absorber for Fully Controlled Suspension System: (a) desired damping force signal (b) supplied control current signal

Table 5. RMS values for quarter car model at $40 \mathrm{~km} / \mathrm{hr}$

\begin{tabular}{ccccc}
\hline Parameter & Passive & $\begin{array}{c}\text { Primary } \\
\text { Suspension } \\
\text { Controlled }\end{array}$ & $\begin{array}{c}\text { Secondary } \\
\text { Suspension } \\
\text { Controlled }\end{array}$ & Fully Controlled \\
\hline$\ddot{z}_{1}$ & 5.0733 & 3.4146 & 3.4878 & 2.1454 \\
& & $(-32.69 \%)$ & $(-31.25 \%)$ & $(-57.71 \%)$ \\
$z_{1}$ & 0.0528 & 0.0349 & 0.0358 & 0.0217 \\
& & $(-33.90 \%)$ & $(-32.20 \%)$ & $(-58.90 \%)$ \\
$z_{1}-z_{2}$ & 0.0359 & 0.0242 & 0.0235 & 0.0147 \\
& & $(-32.59 \%)$ & $(-34.54 \%)$ & $(-57.71 \%)$ \\
\hline
\end{tabular}


Table 6. Peak values for quarter car model at $40 \mathrm{~km} / \mathrm{hr}$

\begin{tabular}{ccccc}
\hline Parameter & Passive & $\begin{array}{c}\text { Primary } \\
\text { Suspension } \\
\text { Controlled }\end{array}$ & $\begin{array}{c}\text { Secondary } \\
\text { Suspension } \\
\text { Controlled }\end{array}$ & Fully Controlled \\
\hline$\ddot{z}_{1}$ & 8.0743 & 5.1417 & 6.1618 & 3.6514 \\
& & $(-36.32 \%)$ & $(-23.69 \%)$ & $(-54.78 \%)$ \\
$z_{1}$ & 0.0901 & 0.0528 & 0.0565 & 0.034 \\
& & $(-41.40 \%)$ & $(-37.29 \%)$ & $(-62.26 \%)$ \\
$z_{1}-z_{2}$ & 0.0582 & 0.0365 & 0.0374 & 0.0233 \\
& & $(-37.29 \%)$ & $(-35.74 \%)$ & $(-59.97 \%)$ \\
\hline
\end{tabular}

The calculated response results in mathematical data are shown in Table 5 having RMS values and in Table 6 having Peak values. In both considered results, all values for three controlled suspension systems are lower compared to uncontrolled one. But the results delivered by fully controlled suspension system are much better compared to primary suspension controlled system as well as secondary suspension controlled systems. Thus, fully controlled system suppresses the passenger seat vibrations in best way compared to uncontrolled system, in terms of RMS and Peak values while passenger seat acceleration $\left(\ddot{z}_{1}\right)$, displacement $\left(z_{1}\right)$ and secondary suspension deflection $\left(z_{1}-z_{2}\right)$ are taken into account.

\section{CONCLUSION}

Present research work has taken the passenger ride comfort factor into account where acceleration and displacement response of passenger seat is studied. For simulation purpose, uncontrolled and different controlled quarter car systems with three-degrees-of-freedom are designed. Simulation response results in graphical and mathematical form show that the fully controlled quarter car system provides best results in vibration suppression of passenger seat compared to primary suspension controlled, secondary suspension controlled and uncontrolled cases. The calculated results of passenger seat as well as secondary suspension system response in terms of RMS values as well as peak values shows that the fully controlled quarter car system provides best performance in terms of vibration suppression of passenger seat compared to other considered cases. Thus, fully controlled system having the assembly of Fuzzy controller and MR shock absorber in both primary and secondary suspension system can be used practically in vehicle system to get best ride comfort experience by passengers during travelling period.

\section{REFERENCES}

[1]Z. Lou., R.D. Ervin and F.E. Filisko, (1994) "A preliminary parametric study of electrorheological dampers”, Trans. ASME J. Fluids Eng. 116 (3), pp. 570-576.

[2]S.A. Hassan and R.S. Sharp, (1986) "The relative performance capability of passive, active and semiactive car suspension systems". SAE technical paper series 864901.

[3]Z.D. Xu, Y.P. Shen, and Y.Q. Guo, (2003) "Semi-active control of structures incorporated with magnetorheological dampers using neural networks", Smart Mater. Struct. 12(1), pp. 80-87.

[4]C.M.D. Wilson and M.M. Abdullah, (2010) "Structural vibration reduction using self-tuning fuzzy control of magnetorheological dampers”, Bull. Earthquake Eng. 8(4), pp. 1037-1054.

[5]X.B. Song, M. Ahmadian, S. Southward, and L.R. Miller, (2005) "An adaptive semiactive control algorithm for magnetorheological suspension systems”, J. Vib. Acoust.-Trans. ASME 127(5), pp. $493-502$. [6]M. Ahmadian and J.C. Poynor, (2001) "An evaluation of magneto rheological dampers for controlling gun recoil dynamics”, Shock Vib. 8(3-4), pp. 147-155. 
[7]S.B. Choi, H.S. Lee, Y.P. Park, (2002) "H-infinity control performance of a full-vehicle suspension featuring magnetorheological dampers", Vehicle System Dynamics 38 (5), pp. 341-360.

[8]M. Yokoyama, J.K. Hedrick, S. Toyama, (2001) "A model following sliding mode controller for semiactive suspension systems with MR dampers", in: Proceedings of the American Control Conference, pp. 2652-2657.

[9]K.M. Choi, S.W. Cho, H.J. Jung, and I. W. Lee, (2004) "Semi-active fuzzy control for seismic response reduction using magnetorheological dampers”, Earthquake Eng. Struct. Dyn. 33(6), pp. 723-736.

[10]J. Yang, J. Li and Y. Du, (2006) "Adaptive fuzzy control of lateral semi-active suspension for highspeed railway vehicle”, In: Comput. Intell., Pt. 2, Proc. Lecture Notes in Computer Science, 4114, pp. 1104-1115. Springer, Berlin.

[11]K.C. Schurter and P.N. Roschke, (2001) "Neuro-fuzzy control of structures using acceleration feedback", Smart Mater. Struct. 10(4), pp. 770-779.

[12]M. Ahmadian and C.A. Pare, (2000) "A quarter-car experimental analysis of alternative semiactive control methods”, J. Intell. Mater. Syst. Struct. 11(8), pp. 604-612.

[13]B.F. Spencer Jr., S.J. Dyke, M.K. Sain, J.D. Carlson, (1997) "Phenomenological model for magnetorheological dampers", Journal of Engineering Mechanics 123 (3), pp. 230-238.

[14]K.C. Schurter, P.N. Roschke, (2000) "Fuzzy modeling of a magnetorheological damper using ANFIS", in: Proceedings of the IEEE International Conference on Fuzzy Systems, pp. 122-127.

[15]S.B. Choi, S.K. Lee, Y.P. Park, (2001) "A hysteresis model for the field-dependent damping force of a magnetorheological damper", Journal of Sound and Vibration 245 (2), pp. 375-383.

[16]C. Sakai, H. Ohmori, and A. Sano, (2003) "Modeling of MR Damper with Hysteresis for Adaptive Vibration Control", 42nd IEEE Conference on Decision and Control, Maui,.

[17]C.C. Chang, P. Roschke, (1998) "Neural network modeling of a magnetorheological damper", Journal of Intelligent Material Systems and Structures 9 (9), pp. 755-764.

[18]C.C. Chang, L. Zhou, (2002) "Neural network emulation of inverse dynamics for a magnetorheological damper", Journal of Structural Engineering 128 (2), pp. 231-239.

[19]N.M. Wereley, L. Pang, G. Kamath, (1998) "Idealized hysteresis modeling of electrorheological and magnetorheological dampers", Journal of Intelligent Material Systems and Structures 9 (8), pp. 642-649.

[20]E.R.Wang, X.Q. Ma, S. Rakhela, and C.Y. Su, (2003) "Modelling the hysteretic characteristics of a magnetorheological fluid damper”, Proc. Inst. Mech. Eng. D, J. Automob. Eng. 217(D7), pp. 537-550.

[21]H.Wang and H.Y. Hu, (2006) "The fuzzy approximation of MR damper (in Chinese)", J.Vib. Eng. 19(1), pp. 31-36.

\section{Authors}

Devdutt is $\mathrm{PhD}$ student in the Department of Mechanical Engineering, YMCA University of Science and Technology, Faridabad, Haryana, India. Presently he is working as Assistant Professor in the Department of Mechanical Engineering, Faculty of Engineering and Technology, Manav Rachna International University, Faridabad, Haryana, India. His research areas of interest are noise, vibration and ride quality related to semi-active and active vehicle suspension system.

Dr. M.L.Aggarwal has done B.Sc. (Mechanical Engg.) from REC Kurukshetra, Haryana, India in 1988, M.Tech. and Ph.D. from IIT New Delhi in 2003 and JMI New Delhi in 2007 respectively. He has been working in YMCA University of Science \& Technology Faridabad, Haryana, India since 1989. He has published 40 papers in International / National Journals in the relevant areas of design engineering. His research areas of interest are

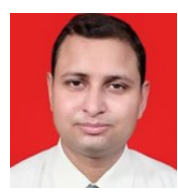
materials, shot peening and design. 